\title{
LEARNING TO PORTRAY YOUR REALITY: TEACHING STATISTICS TO HIGH SCHOOL STUDENTS
}

\author{
Ana Maria Nogales Vasconcelos, Cauan Braga da Silva Cardoso \\ and Isabella Cristine Figueiredo Vieira \\ University of Brasilia, Brazil \\ cauan.br@gmail.com
}

The Institutional Scientific Initiation Scholarship Program (PIBIC) "Learning to Portray Your Reality" seeks to motivate female high school students to apply for undergraduate program in statistics at the University of Brasilia (UnB), to divulge the undergraduate program in statistics at $U n B$ and to promote the statistical education. The high school students learned how to have a statistical thinking, what is the job of a statistician and the roll of statistic in science, as well as some basics concepts of statistics. They also learned how to work with the database available online by the Brazilian Institute of Geography and Statistics (IBGE). Furthermore, it was designed an activity to promote the undergraduate program in statistics at UnB and the learning of the statistic in their school.

\section{INTRODUCTION}

The undergraduate program in statistics of the Department of Statistics at the University of Brasilia (UnB) is, among the exact sciences undergraduate programs, the least popular program. In the past admissions exams to select students for the undergraduate programs at UnB, statistics remained as the least competitive program between exact sciences and engineering undergraduate programs. Others universities in Brazil that offer the program follow a similar pattern in their entrances exams, even though "Statistics" has become more popular in the media.

In this sense, the Institutional Scientific Initiation Scholarship Program (PIBIC) "Learning to Portray Your Reality" seeks to motivate female high school students from Paranoa to apply for undergraduate program in statistics at $\mathrm{UnB}$, to divulge the undergraduate program in statistics at UnB in the public school CEM 01 of Paranoa and to promote the statistical education.

Paranoa is one of the poorest Administrative Region of Brasilia. It has an estimated population of 45.613 habitants in 2013 (CODEPLAN, 2013). Young people compose about $20 \%$ of the population.

Some results in surveys conducted by UnB shows that exact sciences and engineering undergraduate programs attract, in general, male students: $70 \%$ of the applicants to undergraduate programs in exact sciences and engineering in 2012 were man (source: CESPE-UnB). In the case of statistics, the sex ratio is more balanced. This minor polarization regarding gender could be an opportunity to encourage female high school students to ingress in the program.

\section{DESIGN AND ASSESMENT}

This project was coordinated by Professor Ana Maria Nogales Vasconcelos of the Department of Statistics at UnB. It worked with 4 female high school students from the same school (C.E.M. 01 of Paranoa), age (16 years old), grade ("segundo ano", equivalent to the eleventh grade in the U.S.) and socioeconomic level; 1 female secondary school teacher from C.E.M. 01 of Paranoa; 1 female undergraduate statistics student at UnB; and the Youth Observatory of UnB (OJ) team. Each student received a financial assistance from the National Counsel of Technological and Scientific Development (CNPq). The meetings took place mostly at the university campus.

This PIBIC has a Problem-based learning methodology to increase the likelihood of students being motivated to learn. They confront real-world challenges and look for a reasonable solution based on application of knowledge and skills deemed necessary to address the issue (Barrows, 1996). They learned how to solve statistical problems computationally through Microsoft Office Excel.

Some meeting were planned to occur outside the campus, aiming a more attractive learning atmosphere (Bowell \& Eison, 1991). The high school students visited the Brazilian Institute of Geography and Statistics (IBGE) to know better the labor market for statisticians; they also visited 
an exposition about the Brazilian Cerrado in the Bank of Brazil Cultural Center (CCBB), to learn the role of statistics in different knowledge areas. The result of such an approach to teaching is that learners are motivated to persist at authentic problems, meld prior knowledge and experience with new learning, and develop rich domainspecific knowledge and thinking strategies to apply to realworld problems (Blumenfeld, et al., 1991)

Finally, the undergraduate students in statistics involved in the project designed various activities to teach statistics at the CEM 01 of Paranoa and to promote the undergraduate program in statistics to high school students. These activities were first tested with an audience of 15 people, amongst high school students and teachers. The female high school students then applied the activities to their peers in class, assisted by the undergraduate students, to demonstrate their ability to use knowledge in the ways in which scholars or professionals do (Wiggins, 1998).

\section{IMPORTANCE}

The female high school students visited the UnB campus for the first time because of the project. This approximation brought a new perspective to them, not only presenting the undergraduate program in statistics, but also showing the access to undergraduate programs at UnB as a dream that can come true.

\section{GROUP ACTIVITIES}

The activities below were designed during the execution of the project in order to teach basic concepts of statistics to high school students from C.E.M. 01 of Paranoa, to promote the undergraduate program in statistics at $\mathrm{UnB}$ and the learning of the statistic in their school.

All activities were planned to work with up to 40 students, divided in groups with a minimum 4 and maximum 8 students. They were previously tested with a group of 15 students, They are listed in order of recommended execution.

\section{Activity 1: Working with the concepts of sample and population \\ Level of difficulty: easy. \\ Materials: disposable cups, one big recipient, assorted colors candies, papers and pens.}

Students are asked to form groups and for each is given a disposable cup that will simulate their "estimator". The assorted colors candies are mixed up in a proper recipient in different proportions and one color must be the majority in the recipient. All the proportions must be noted down previously. Each color will represent a population and is presented as so to the students. Then, each group collect their sample with their "estimators" (cups) and are asked to estimate the color that is the majority in the recipient through it. Furthermore, all the answer are written down and the groups compare their answers. By determining the proportion of colors through a sample, they estimate the parameters of the population. The differences between the answers of each group is mainly caused by chance when the candies are properly randomized. Students thus begin to develop an intuitive understanding of the idea of survey, estimation and estimator, and have learn in practice the statistical concepts of population and sample.

The activity can be increased showing the students the better approximation of the estimation assembling all the samples. The objective is to show the relationship between the size of the sample and the accuracy of the estimation. Also, the concept of variability in populations and the role of statistics to approximate the reality through estimation.

\section{Activity 2: Working with the concept of measures of central tendency (mean, median and mode) Level of difficulty: easy. \\ Materials: calculator, papers and pens.}

A group of students gives information about their height, weight and/or age. The information are written down and for each is calculated the mean, median and mode. All the students can follow up the calculus involved for each concept. Next, the group is ordered in a straight line by their height and the mean calculated is located in the line formed. The same is made with the median and the mode. Then, all three measurements are compared and the students are 
asked to discuss the results: what type of information the mean, median and mode give to us? Is it possible that all three have the same value? When will this occur? This questions lead to an initial idea of symmetric and asymmetric distributions. The activity can be repeated using the weights and ages of the students.

It is important that the students notice the difference between the measures of central tendency. This activity can be increased by adding other students or removing some of them from the line to show the robustness of the mode over the median and the median over the mean.

\section{Activity 3: Working with the concept of variability \\ Level of difficulty: medium. \\ Materials: calculator, papers and pens.}

The students form the same group from Activity 1 again. Each group will create a histogram of the height, weight and/or age of its members. In each histogram, they must locate the mean, median and mode. Then, all groups compare their answers. Which has the most symmetric distribution? Which has the most asymmetric? What is the difference between the mean, median and mode in each histogram? Why did that happen? By answering these questions, the students introduce themselves to the concept of variability and have a visual example of symmetric and skewed distributions.

It is possible that the students have some difficulty in making a histogram. If this activity will take place, it may be necessary to make an example first of how a histogram is designed. If so, the heights, weights and age from the students of Activity 2 could be used for mounting the first histogram to start this activity.

\section{Activity 4: Working with the concept of measures of dispersion (variance and standard deviation) Level of difficulty: medium/hard. \\ Materials: PET bottle or similar, calculator, papers and pens.}

For each group is determined the variance of the heights, weights and/or ages. The students follow up the variance calculation and are confronted with the question: what does the variance represent? How do we interpret the value found? A PET bottle or similar is placed in the middle of the group and the students to represent the "mean" of the distribution, and each student takes distance from the bottle according to its deviation from the mean. It does not need to be accurate. The objective is to show the roll of variance in the description of the data and the difference between variance and standard deviation.

This activity may be a problem if there are numerous students and/or there is little space. If so, it can be made with only one group at a time or with few students, with the others helping with the calculation and with the positioning of the students after.

\section{CLASS ACTIVITY}

This activity was designed at the end of the project and was implemented in high school classes at CEM 01 of Paranoa, with an average of 30 students per class, all of them in the last year of high school.

This activity involved an adapted roulette divided in four areas, as shown in the Figure 1 below. The class was first introduced to the project, the students participants and the undergraduate program in statistics at UnB. Then, the class was divided in up to six groups and each group received a name. The groups take turns to spin the roulette. 


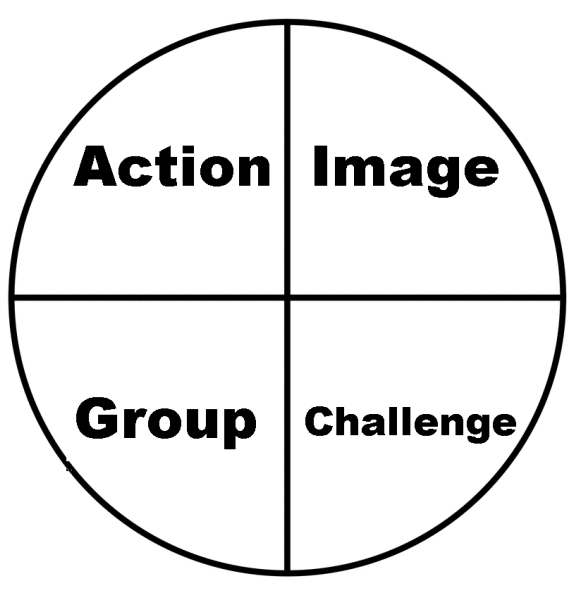

Figure 1 - Schematic drawing of the roulette

When the roulette stops at the "Action" area, all groups must answer a question about Brazilian reality, such as guess the percentage of people that has some disability, which gender is more educated or the meaning of some statistical concept. When it stops at the "Image" area, all groups must draw a graphic on the blackboard about some given information, mainly about demography of Brazil. When it stops at the "Group" area, only the group that spun the roulette can answer the question, which also involved Brazilian demography subjects. When it stops at the "Challenge" area, all groups must calculate a mean, give the definition of some basic statistic concept or solve a question taken from the National High School Exam of Brazil (ENEM) that involves math.

\section{CONCLUSION}

This new approach of teaching statistics intends also approach high school students and university, especially those in a situation of vulnerability. This project works with the public school of Paranoa, which holds the second most vulnerable youth of Brasilia (Schumann, 2014). The high school students learned how to have a statistical thinking, what is the job of a statistician and the roll of statistic in science, as well as some basics concepts of statistics. They also learned how to work with the database available online by the Brazilian Institute of Geography and Statistics (IBGE). Furthermore, they developed an activity to promote the undergraduate program in statistics at UnB and the learning of the statistic in their school.

\section{REFERENCES}

Barrows, H. S. (1996). Problem-based learning in medicine and beyond: A brief overview. In L. Wilkerson \& W. H. Gijselaers (Eds.), Bringing problem-based learning to higher education: Theory and practice (pp. 3-12). San Francisco: JosseyBass.

Bonwell, C. C., Eison, J. A. (1991). Active Learning: Creating Excitement in the Classroom, ASHE-ERIC Higher Education Report No. 1. Washington, D.C.: The George Washington University, School of Education and Human Development.

Blumenfeld, P., Soloway, E., Marx, R., Krajcik, J., Guzdial, M., \& Palincsar, A. (1991). "Motivating Project- Based Learning: Sustaining the Doing, Supporting the Learning." Educational Psychologist, $26(3$ \& 4), 369-398.

Companhia de Planejamento do Distrito Federal - CODEPLAN (2013). Pesquisa Distrital por Amostragem de Domicílios: Paranoá. 66 pp.

Schumann, L. (2014). A multidimensionalidade da construção teórica da vulnerabilidade: análise histórico-conceitual e uma proposta de índice sintético. Graduate - [s.l.] University of Brasilia.

Wiggins, G (1998). Educative Assessment: Designing Assessments to Inform and Improve Student Performance. San Francisco: Jossey-Bass. 